Hydrol. Earth Syst. Sci., 17, 1079-1091, 2013

www.hydrol-earth-syst-sci.net/17/1079/2013/

doi:10.5194/hess-17-1079-2013

(C) Author(s) 2013. CC Attribution 3.0 License.

\title{
Improving operational land surface model canopy evapotranspiration in Africa using a direct remote sensing approach
}

\author{
M. Marshall ${ }^{1}$, K. Tu ${ }^{2}$, C. Funk ${ }^{1}$, J. Michaelsen ${ }^{1}$, P. Williams ${ }^{1}$, C. Williams ${ }^{3}$, J. Ardö ${ }^{4}$, M. Boucher ${ }^{5}$, B. Cappelaere ${ }^{5}$, \\ A. de Grandcourt ${ }^{6,7}$, A. Nickless ${ }^{8}$, Y. Nouvellon ${ }^{6,7}$, R. Scholes ${ }^{8}$, and W. Kutsch ${ }^{9}$ \\ ${ }^{1}$ Department of Geography, Climate Hazards Group, UC Santa Barbara, Santa Barbara, CA, USA \\ ${ }^{2}$ Department of Integrative Biology, 4007 VLSB, UC Berkeley, Berkeley, CA, USA \\ ${ }^{3}$ Department of Geography, Clark University, Worcester, MA, USA \\ ${ }^{4}$ Department of Earth and Ecosystem Sciences, Division of Physical Geography and Ecosystem Analysis, Lund University, \\ Sölvegatan 12, 22362 Lund, Sweden \\ ${ }^{5}$ Institut de recherche pour le développement, HydroSciences, BP 64501, 34394 Montpellier Cedex 5, France \\ ${ }^{6}$ CIRAD, Persyst, UPR80, 34398 Montpellier Cedex 5, France \\ ${ }^{7}$ CRDPI, BP 1291, Pointe-Noire, Republic of Congo \\ ${ }^{8}$ Natural Resources and the Environment, Council of Scientific and Industrial Research, Pretoria, South Africa \\ ${ }^{9}$ Johann Heinrich von Thünen Institute, Institute for Agricultural Climate Research, Bundesallee 50, \\ 38116 Braunschweig, Germany
}

Correspondence to: M. Marshall (marshall@geog.ucsb.edu)

Received: 14 December 2011 - Published in Hydrol. Earth Syst. Sci. Discuss.: 2 February 2012

Revised: 1 February 2013 - Accepted: 11 February 2013 - Published: 12 March 2013

\begin{abstract}
Climate change is expected to have the greatest impact on the world's economically poor. In the Sahel, a climatically sensitive region where rain-fed agriculture is the primary livelihood, expected decreases in water supply will increase food insecurity. Studies on climate change and the intensification of the water cycle in sub-Saharan Africa are few. This is due in part to poor calibration of modeled evapotranspiration (ET), a key input in continental-scale hydrologic models. In this study, a remote sensing model of transpiration (the primary component of ET), driven by a time series of vegetation indices, was used to substitute transpiration from the Global Land Data Assimilation System realization of the National Centers for Environmental Prediction, Oregon State University, Air Force, and Hydrology Research Laboratory at National Weather Service Land Surface Model (GNOAH) to improve total ET model estimates for monitoring purposes in sub-Saharan Africa. The performance of the hybrid model was compared against GNOAH ET and the remote sensing method using eight eddy flux towers representing major biomes of sub-Saharan Africa. The greatest improvements in model performance were at humid sites with dense vegetation, while performance at semi-arid sites was
\end{abstract}

poor, but better than the models before hybridization. The reduction in errors using the hybrid model can be attributed to the integration of a simple canopy scheme that depends primarily on low bias surface climate reanalysis data and is driven primarily by a time series of vegetation indices.

\section{Introduction}

Precipitation and evapotranspiration (ET) are the processes by which water moves across the land and atmosphere interface, the latter being primarily a biophysical response (Hartmann, 1994; note: acronyms are listed and explained in Table 1, as they appear in the text). In the Sahel, latent energy (LE: ET energy equivalent) during the rainy season is the primary regulator after solar forcing of energy balance seasonal variability, the strength of which changes significantly across land cover types (Ramier et al., 2009). At interannual and interdecadal timescales, the impact of ET on the energy balance is more significant than solar forcing, which after sea surface temperatures, explains much of the rainfall variability in the region (Zeng and Neelin, 2000). This 
is due to strong coupling between soil moisture and rainfall. A decrease in rainfall and natural vegetation cover leads to an increase in surface albedo and decrease in ET, which can decrease moisture input to the West African monsoon, thus contributing to persistent droughts there (Zeng, 2003). Declines in ET have been simulated over much of the Sahel and correspond to a decoupling of ET from precipitation with rising surface temperatures (Marshall et al., 2012a). Understanding ET and its relationship to rainfall is therefore climatologically important in the region, particularly to farmers who make up $70 \%$ of the continent's livelihoods (World Bank, 2000) and rely almost entirely on rain (>95\%) to grow their crops (FAOSTAT, 2010). Near real-time ET estimates driven by regional-scale vegetation dynamics therefore can be a powerful tool to promote early warning response to food insecurity, while remote sensing-based and operational land surface modeling approaches utilize free and globally available data, which overcome the institutional and infrastructural limitations of ground data collection in the region.

Literature reviews of regional to global scale ET modeling techniques can be found in Diak et al. (2004), Glenn et al. (2007), Jiménez et al. (2011), Kalma et al. (2008), and Mueller et al. (2011). Remote sensing-based modeling techniques use near real-time visible, near infrared, and/or thermal sensor and typically some meteorological data to estimate LE as a residual of the energy balance. The vegetation fraction, which is the primary control on ET, can be updated with readily available remote sensing data, while meteorological forcing can be estimated from ground, meteorological satellite, and surface climate reanalysis data. Operational Land Surface Models (LSMs), like remote sensingbased methods, provide near real-time continuous and global estimates of ET using process-based techniques driven by assimilated ground, satellite, and surface climate reanalysis data (Rodell et al., 2004). Unlike remote sensing-based models, ET is driven primarily by precipitation, with ET being solved as a residual of the water balance and corrected using assimilated fields of the energy terms (Chen et al., 1996).

Remote sensing-based modeling techniques can be divided into two broad categories: empirical and physicsbased. Physics-based approaches can be further subdivided into indirect and direct. Empirical remote sensing-based approaches (e.g. Wang et al., 2007) either develop a statistical model dependent on vegetation indices (e.g. the Normalized Difference Vegetation Index - NDVI) alone or in combination with other ET drivers (e.g. net radiation and land surface temperature). Empirical approaches suffer from transferability and scale-dependent non-linearity, as the models are tuned to areas at a particular resolution with unique phenological characteristics. Indirect approaches combine remote sensing derived energy flux with ancillary meteorological data using physically based relationships to estimate ET as a residual of the energy balance. Indirect models are either single source (e.g. Surface Energy Balance Algorithm for Land: Bastiaanssen et al., 1998), meaning vegetation and soil are considered as a single pixel, or two source (e.g. Atmospheric Land Exchange Inverse Model; Anderson et al., 1997), meaning vegetation and soil are considered at the sub-pixel level. Indirect methods, though accurate at multiple scales, can be highly uncertain in heterogeneous regions and difficult to implement operationally at regional to global scales, because of land surface temperature uncertainty and scale dependencies, as well as the need for extensive groundbased meteorological data (Kite and Droogers, 2000). Direct remote sensing methods have been gaining popularity, as they do not suffer from scale dependencies and can readily be driven by global scale data. Direct approaches estimate ET using a series of energy and moisture constraints on atmospheric demand (i.e. potential evapotranspiration - PET). Algorithms which produce global estimates of ET in this way are detailed in Nishida et al. (2003), Leuning et al. (2008), $\mathrm{Mu}$ et al. (2007a), and Fisher et al. (2008). These models have been used in sub-Saharan Africa to estimate water use efficiency for arid rangelands (Palmer and Yanusa, 2011) and to extrapolate biological nitrogen deposition from wildfires (Chen et al., 2010). The major drawback of these approaches and remote sensing methods in the tropics in general is the presence of cloud cover, which can often obscure a target from the sensor for several days. Land surface models overcome this drawback by using long-term monthly averages of remote sensing data and simulated alternatives.

The AMMA (African Monsoon Multidisciplinary Analysis) Land-Surface Model Inter-comparison Project (Boone et al., 2009) uses LSMs to better understand the impact of energy and moisture flux on the West African monsoon. Land surface models use a highly parameterized and multi-layer resistance-based approach to determine ET. Specifically, ET for one or multiple leaf layers is a function of light use efficiency, stomatal resistance to water loss and plant stress, atmospheric resistance to diffusion across the plant interface, and atmospheric resistance to turbulent moisture in the surface boundary layer (Anderson et al., 2000). Two of the major drawbacks of LSMs is that their strong theoretical framework can lead to greater uncertainty than remote sensing methods, due to conspiring factors attributed to a multitude of data types (most importantly $R_{\mathrm{N}}$ ) and lack of groundbased validation data in the region of interest (Rosero et al., 2009). In addition, transpiration (the primary component of ET) is driven by long-term monthly averages of NDVI, which can increase bias in semi-arid regions with high seasonal variability (Hogue et al., 2005).

Given the limitations of direct remote sensing and land surface modeling approaches for estimating ET, the objective of this paper is to demonstrate how the two approaches can be combined to create a hybrid which improves ET estimates across Africa. Examples of model hybridization include combining land surface temperature derived from remote sensing data with a soil vegetation atmosphere transfer model in Olioso et al. (1999) and an indirect, remote-based model in Boni et al. (2001). Evapotranspiration estimates in 
Table 1. Acronyms and their definitions in order of appearance.

\begin{tabular}{ll}
\hline Acronym & Definition \\
\hline ET & Evapotranspiration \\
LE & Latent Heat \\
LSM & Land Surface Model \\
NDVI & Normalized Difference Vegetation Index \\
PET & Potential Evapotranspiration \\
AMMA & African Monsoon Multidisciplinary Analysis \\
PT-JPL & Priestley-Taylor Jet Propulsion Laboratory Model \\
NOAH & National Centers for Environmental Prediction, \\
& Oregon State University, Air Force, and Hydrology \\
& Research Laboratory at National Weather Service \\
& Model \\
EVI & Enhanced Vegetation Index \\
SAVI & Soil-Adjusted Vegetation Index \\
$T$ MAX & Daytime Temperature \\
PAR & Photosynthetically Active Radiation \\
LAI & Leaf Area Index \\
MODIS & Moderate Resolution Imaging Spectroradiometer \\
AVHRR & Advanced Very High Resolution Radiometer \\
VPD & Vapor Pressure Deficit \\
RH & Relative Humidity \\
$p$ & Surface Pressure \\
$q$ & Specific Humidity \\
GLDAS & Global Land Data Assimilation System \\
LIS & Land Information System \\
GNOAH & GLDAS realization of NOAH \\
IGBP & International Geosphere-Biosphere Programme \\
$H$ & Sensible Heat \\
\hline &
\end{tabular}

this study are improved further downstream in the modeling process by direct insertion using the Priestley-Taylor Jet Propulsion Laboratory (PT-JPL) (Fisher et al., 2008) direct remote sensing approach and National Centers for Environmental Prediction, Oregon State University, Air Force, and Hydrology Research Laboratory at National Weather Service (NOAH) LSM (Chen et al., 1996). Specifically, NOAH's sophisticated transpiration component, driven by long-term average NDVI and surface climate reanalysis, is substituted with PT-JPL's simple transpiration scheme, driven by a time series of NDVI and the Enhanced Vegetation Index (EVI) and surface climate reanalysis. NOAH is comparable to other LSMs when modeling LE over large areas in western Africa (Boone et al., 2009) and generally performs better than other LSMs under semi-arid (sub-tropical) conditions (Hogue et al., 2005). Unlike other remote sensing-based approaches, PT-JPL does not employ the evaporative fraction, which is used to extrapolate ET from once-a-day or coarser temperature and energy flux measurements, and can be a major source of error, as the evaporative fraction is assumed constant over the time frame, which is rarely the case (Gentine et al., 2011). The PT-JPL model tends to outperform other ET models in the tropics (Fisher et al., 2009) when driven and evaluated using observed data. It can be run readily using remote sensing and surface reanalysis data over large areas, though the sensitivity of the model with coarser resolution surface climate reanalysis data has not been evaluated.

\section{Methods}

\subsection{The PT-JPL model for Evapotranspiration}

The PT-JPL model is based on the Priestley and Taylor (1972) model for PET, then introduces ecophysiological constraint functions to reduce PET to ET. A complete description of the model and bibliography of model component origins can be found in Fisher et al. (2008). The PriestleyTaylor formulation for PET reduces the advection term in the original Penman (1948) formulation to a coefficient $(\alpha)$. $\alpha$ is empirically derived and assumes the ratio of PET to equilibrium PET (no advection) is constant. The Priestley-Taylor model is therefore driven primarily by net radiation $\left(R_{\mathrm{N}}\right)$ and tends to perform best in humid areas and worse in arid areas, due in part to the equilibrium assumption (DehghaniSanij et al., 2004). The PT-JPL model retains the original $\alpha$ (1.26) and uses six parameters to modify PET for both humid and arid areas. The equations have been arranged to express LE in terms of its three components: bare soil evaporation $\left(\mathrm{LE}_{S}\right)$, transpiration $\left(\mathrm{LE}_{\mathrm{C}}\right)$, and wet surface evaporation $\left(\mathrm{LE}_{\mathrm{I}}\right)$ :

$$
\begin{aligned}
\mathrm{LE}_{\mathrm{S}} & =f_{\mathrm{SM}}\left(1-f_{\mathrm{WET}}\right)\left(1-f_{\mathrm{C}}\right) \frac{\alpha \Delta}{\Delta+\gamma}\left(R_{\mathrm{N}}-G\right) \\
\mathrm{LE}_{\mathrm{C}} & =f_{\mathrm{C}} f_{\mathrm{G}} f_{\mathrm{T}} f_{\mathrm{M}}\left(1-f_{\mathrm{WET}}\right) \frac{\alpha \Delta}{\Delta+\gamma}\left(R_{\mathrm{N}}\right) \\
\mathrm{LE}_{\mathrm{I}} & ==f_{\mathrm{C}} f_{\mathrm{WET}} \frac{\alpha \Delta}{\Delta+\gamma}\left(R_{\mathrm{N}}\right),
\end{aligned}
$$

where $f_{\mathrm{SM}}, f_{\mathrm{WET}}, f_{\mathrm{C}}, f_{\mathrm{G}}, f_{\mathrm{T}}$, and $f_{\mathrm{M}}$ are the soil moisture constraint, relative surface wetness, fractional total vegetation cover, green canopy fraction, plant temperature constraint, and the plant moisture constraint, respectively. Table 2 lists each parameter and the relevant equation used in the computation of LE. The psychometric constant $(\gamma$ : $0.066 \mathrm{kPa}^{\circ} \mathrm{C}^{-1}$ ), slope of the saturation-to-vapor pressure curve $(\Delta), R_{\mathrm{N}}$, and $G$ make up the Priestley-Taylor formulation for PET. Equation (1) is a modified version of the original PT-JPL model, in which the soil and canopy contribution to $R_{\mathrm{N}}$ are assumed to be a function of leaf area index (LAI) and $f_{\mathrm{C}}$ according to Beer's Law (Kelliher et al., 1995). Here, $R_{\mathrm{N}}$ is discretized by NDVI, which has been shown to be highly correlated with $f_{\mathrm{C}}$ (Sellers, 1987). Fractional total vegetation cover is expressed as a linear function of NDVI, which is determined from the red and near-infrared bands of standard multi-spectral remote sensing platforms. In Fisher et al. (2008), the Soil-Adjusted Vegetation Index (SAVI) was used instead of EVI to estimate the fraction of Photosynthetically Active Radiation (PAR) absorbed by green vegetation $\left(f_{\mathrm{APAR}}\right): 1.2 \cdot(1.136 \cdot \mathrm{SAVI}-0.04)$ taken from Gao et al. (2000). The Enhanced Vegetation Index is a remotely 
Table 2. Model parameters and equations for the PT-JPL Model, where $\lambda=T_{\mathrm{OPT}}, m_{1}=1.2, m_{2}=1.0, b_{2}=-0.05$, and $\beta=1.0$.

\begin{tabular}{lll}
\hline Parameter & Description & Equation \\
\hline$f_{\mathrm{c}}$ & Fractional total vegetation cover & $f_{\mathrm{IPAR}}$ \\
$f_{\mathrm{g}}$ & Green canopy fraction & $f_{\mathrm{APAR}} / f_{\mathrm{IPAR}}$ \\
$f_{T}$ & Plant temperature constraint & $e^{-\left(\frac{T_{\mathrm{MAX}}-T_{\mathrm{OPT}}}{\lambda}\right)^{2}}$ \\
$f_{\mathrm{M}}$ & Plant moisture constraint & $f_{\mathrm{APAR}} / f_{\mathrm{APAR}, \mathrm{MAX}}$ \\
$f_{\mathrm{APAR}}$ & Fraction of PAR absorbed by green vegetation cover & $m_{1} \mathrm{EVI}$ \\
$f_{\mathrm{IPAR}}$ & Fraction of PAR intercepted by total vegetation cover & $m_{2} \mathrm{NDVI}+b_{2}$ \\
$f_{\mathrm{SM}}$ & Soil moisture constraint & $\mathrm{RH}$ \\
$f_{\mathrm{wet}}$ & Relative surface wetness & $\mathrm{RH}$ \\
$T_{\mathrm{opt}}$ & Optimum plant growth temperature & $T_{\mathrm{MAX}}$ at max $\left\{\mathrm{PAR} \times f_{\mathrm{APAR}} \times T_{\mathrm{MAX}} / \mathrm{VPD}\right\}$ \\
\hline
\end{tabular}

sensed spectral index that is more sensitive to the chlorophyll content of vegetation than NDVI and can be derived from the Moderate Resolution Imaging Spectroradiometer (MODIS) Earth Observing System-Terra platform (Huete et al., 2002). Another modification includes $f_{\text {wet }}$, a function raised to the power of 4 in the original paper, changed to the power of 10 in this paper, because it was determined to be the optimal value when compared with observed ET. It assumes that the surface is not wet at a higher relative humidity than by using 4 in areas with extreme temperatures and PET.

The transpiration component of LE has the greatest number of constraints. The green canopy fraction is a biophysical constraint expressed as the ratio of $f_{\mathrm{APAR}}$ to the total amount of PAR absorbed by the canopy $\left(f_{\mathrm{C}}\right)$. The plant temperature constraint is a physiological parameter and assumes that vegetation photosynthesizes at an accelerated rate until an optimal temperature $\left(T_{\mathrm{OPT}}\right)$ is achieved, after which efficiency decreases (June et al., 2004). The optimal temperature is determined over the entire available time series and is analogous to "relative greenness" in the remote sensing literature. It occurs during the primary growing season, when the daytime temperature $\left(T_{\mathrm{MAX}}\right)$ at which plant investment in light energy $\left(f_{\mathrm{APAR}}\right)$ and the availability of light $(\mathrm{PAR})$ are high, and the vapor pressure deficit (VPD) is low. The plant moisture constraint is the ratio of $f_{\mathrm{APAR}}$ to maximum $f_{\mathrm{APAR}}$ over the available time series. It assumes that the amount of light a plant absorbs varies with moisture availability: $f_{\mathrm{APAR}}$ decreases only when the plant is stressed, thus lowering transpiration when PAR is high. The effect of this constraint on $\mathrm{LE}_{\mathrm{C}}$ is minimal, unless the plant is suffering from extreme moisture stress.

The wet canopy and $\mathrm{LE}_{\mathrm{S}}$ components are governed by relative humidity (RH), which can be determined from surface pressure $(p)$ and specific humidity $(q)$ reanalysis. It is assumed that bare soil evaporates water at the potential rate, provided that the soil is saturated (Bouchet, 1963). When the soil is not saturated, relative humidity above the surface decreases and LE decreases due to lower soil water conductivity. The soil moisture constraint is a power of function of RH and VPD, which acts to reduce the supply of water to the atmosphere as the soil dries. Midday relative humidity and VPD are used, because the coupling between soil moisture and atmospheric humidity is strongest at midday when vertical mixing is high. Similarly, $f_{\text {WET }}$ is a power function of relative humidity and indicates the probability that the surface is wet; when relative humidity is $100 \%$, the soil and canopy are completely wetted and evaporate moisture at the potential rate.

\subsection{NOAH Model for Evapotranspiration}

The earliest version of NOAH can be traced back to Chen et al. (1996), who integrated an explicit canopy component with a simple soil water balance model developed at OSU (Pan and Mahrt, 1987). NOAH is a community model which has undergone several intermodel comparisons and groundbased validations, leading to vast improvements in its parameterization since its inception at OSU. These include improvements to bare soil evaporation estimates with the introduction of skin temperature and a dynamic soil moisture component (Betts et al., 1997) and to transpiration estimates with the introduction of a monthly fractional total vegetation cover climatology (Chen and Dudhia, 2001).

As with the PT-JPL model, NOAH includes three components of latent heat. Each energy term $\left(\mathrm{LE}_{\mathrm{S}}, \mathrm{LE}_{\mathrm{C}}\right.$, and $\left.\mathrm{LE}_{\mathrm{I}}\right)$ is summed after constraints on PET have been computed. Potential evapotranspiration in the NOAH model is a modified version of Penman (1948) described in Mahrt and Ek (1984):

$$
\mathrm{LE}=\{\underbrace{\left(1-f_{\mathrm{C}}\right) \beta}_{\mathrm{LES}}+\underbrace{f_{\mathrm{C}} B_{\mathrm{C}}\left(1-\left(\frac{W_{\mathrm{C}}}{S}\right)^{n}\right)}_{\mathrm{LE}_{\mathrm{C}}}+\underbrace{f_{\mathrm{C}}\left(\frac{W_{\mathrm{C}}}{S}\right)^{n}}_{\mathrm{LE}_{I}}\} \mathrm{PET}
$$

where $\beta$ is the fraction of total soil moisture not used by the canopy (Mahfouf and Noilhan, 1991), $B_{\mathrm{C}}$ is a function of atmospheric and stomatal resistance (Jacquemin and Noilhan, 1990), $W_{\mathrm{C}}$ is the water holding capacity of the canopy defined as the residual of water balance terms, and $S$ is the maximum water holding capacity of the canopy (calibrated 
constant). As in the original PT-JPL formulation, $f_{\mathrm{C}}$ is a function of Leaf Area Index (LAI). It is computed from a $0.15^{\circ}$ resolution climatology of Advanced Very High Resolution Radiometer (AVHRR) NDVI (Gutman and Ignatov, 1998). Soil moisture availability $(\beta)$ includes a dynamic soil moisture component constrained by the wilting point and the field capacity of the soil, both of which are functions of soil texture. The constraints are elaborated upon in Table 3, while a more detailed description can be found in Chen and Dudhia (2001).

\subsection{PT-JPL and GNOAH hybrid model}

In the hybrid model, the transpiration component of the PT-JPL model replaces the transpiration component of the GNOAH model:

$\mathrm{LE}=\left[f_{\mathrm{C}} f_{\mathrm{G}} f_{\mathrm{T}} f_{\mathrm{M}}\left(1-f_{\mathrm{WET}}\right)+\left(1-f_{\mathrm{C}}\right) \beta+f_{\mathrm{C}}\left(\frac{W_{\mathrm{C}}}{S}\right)^{n}\right] \mathrm{PET}$

The Penman formulation for PET from GNOAH and $f_{\mathrm{C}}$ from PT-JPL are used to maintain consistency across the two models and three components. The fractional total vegetation from GNOAH is removed and the soil and interception terms are then multiplied by the time-varying PT-JPL $f_{\mathrm{C}}$. Similarly, Priestley-Taylor PET is removed from PT-JPL and the transpiration component is multiplied by GNOAH PET, because the GNOAH (Penman) approach is theoretically more rigorous than Preiestley-Taylor PET and using the later did not show any improvement in the results compared to the former.

\subsection{Data processing and handling}

The PT-JPL model is run globally at a quasi- $0.05^{\circ}$ resolution daily time step from 2000-2008 for sub-Saharan Africa and is aggregated to a monthly time step for visualization and comparison purposes with field data. The choice of resampling to $0.05^{\circ}$ resolution assumes that spatial heterogeneity is driven primarily by vegetation. The vegetation data consisted of 16-day $0.05^{\circ}$ resolution NDVI and EVI derived from reflectance detected by MODIS. A piecewise weighted least squares regression filter (Swets et al., 1999) is applied to the indices to further reduce atmospheric interference on the vegetation signal.

Daily values were aggregated to monthly values for several reasons: (1) ground heat flux was not calculated in the PT-JPL model (ground heat flux is near zero in warm regions at a monthly time step), (2) daily station flux data was often spurious or missing, (3) the vegetation data used is extremely noisy at a daily time step, and (4) monthly timesteps are adequate to address research questions in food security monitoring and other continental scale studies.

The Global Land Data Assimilation System (GLDAS) at $0.25^{\circ}$ resolution is used for the climatological forcing of PT-JPL and NOAH. Global Land Data Assimilation System forcing and parameters (Rodell et al., 2004), enabled by the
Table 3. Model parameters and equations for GNOAH, where $k$ is Beer's Law extinction coefficient, LAI is the leaf area index, $r$ is the atmospheric resistance, $R_{\mathrm{C}}$ is the stomatal resistance, $C_{\mathrm{h}}$ is the surface exchange coefficient for heat and moisture, $\Theta_{1}$ is the soil moisture in the top soil layer at a given timestep, $\Theta_{\mathrm{W}}$ is the wilting point, $\Theta_{\mathrm{REF}}$ is the field capacity, and $f$ is a scaling constant typically equal to 1 or 2 . The change in water holding capacity is defined by $P$ (precipitation), $D$ (drainage) and $\mathrm{LE}_{\mathrm{C}}$ (in mass units).

\begin{tabular}{lll}
\hline Parameter & Description & Equation \\
\hline$f_{\mathrm{C}}$ & Fractional total vegetation cover & $e^{-(k \mathrm{LAI})}$ \\
$B_{\mathrm{C}}$ & Plant coefficient & $\frac{r+\Delta}{r\left(1+C_{\mathrm{h}} R_{\mathrm{C}}\right)+\Delta}$ \\
$\beta$ & Soil moisture availability & $\left(\frac{\Theta_{1}-\Theta_{\mathrm{W}}}{\Theta_{\mathrm{REF}}-\Theta_{\mathrm{W}}}\right)$ \\
$W_{\mathrm{C}}$ & Water holding capacity & $f_{\mathrm{C}} P-D-\mathrm{LE}_{\mathrm{C}}$ \\
$S$ & Maximum water holding capacity & Optimized constant \\
\hline
\end{tabular}

Land Information System (LIS) (Kumar et al., 2006), compute surface fluxes using various LSMs. Details on GLDAS forcing data and model outputs can be found on NASA's Hydrology Data and Information Services Center webpage (http://disc.sci.gsfc.nasa.gov/hydrology). The dataset is primarily used by end-users, as the LIS currently has limited functionality for exploratory research and requires large computational resources. The version of NOAH used (2.7.1) is run offline by the $0.25^{\circ}$ resolution forcing data. It will be referred to as GNOAH for the remainder the paper. GLDAS uses NOAA/GDAS atmospheric fields, Climate Prediction Center Merged Analysis of Precipitation fields, and observation-driven shortwave and longwave radiation using the Air Force Weather Agency's AGRicultural METeorological modeling system. These data are produced at 3-hourly intervals and aggregated to a monthly time step. The latent heat simulation from GNOAH is at $0.25^{\circ}$ resolution and resampled using the "nearest neighbor" approach to $0.05^{\circ}$ resolution for comparison purposes with the PT-JPL model.

Energy and moisture flux and meteorological data was gathered from eight sites representing major land cover types in Africa. Table 4 lists the sites, along with the station identification and name, country, geographic coordinates, the period data is obtained, ecosystem type using the International Geosphere-Biosphere Programme (IGBP) naming convention, and mean climatology. The observed data are from three online sources: AMMA (www.amma-international. org), CarboAfrica (www.carboafrica.net) and Fluxnet (www. fluxdata.org). Five of the sites (BW-Ma1, CG-Euc, NE-Waf, NE-Wam, and ZA-Kru) include half-hourly data needed to run the PT-JPL model: surface air temperature $\left({ }^{\circ} \mathrm{C}\right)$, incoming longwave and shortwave radiation $\left(\mathrm{W} \mathrm{m}^{-2}\right)$, outgoing longwave and shortwave radiation $\left(\mathrm{W} \mathrm{m}^{-2}\right)$, relative humidity $(\%)$, precipitation $(\mathrm{mm})$, and latent heat $\left(\mathrm{W} \mathrm{m}^{-2}\right)$. NE-Wam and NE-Waf were in close proximity and shared a rainfall gauge between them (Ramier et al., 2009). Latent heat flux was measured using the eddy covariance method (Baldocchi et al., 1988). With this technique, LE is 
Table 4. Eight micrometeorological stations throughout sub-Saharan Africa. Ecosystems are identified with the IGBP convention: croplands/natural vegetation mosaic (CRO), evergreen broadleaf forest (EBF), open shrublands (OSH), savanna (SAV), and woody savanna (WSA). $P$ and $T_{\mathrm{A}}$ are the annual total precipitation and average air temperature, respectively.

\begin{tabular}{|c|c|c|c|c|c|c|c|c|c|}
\hline ID & Name & Country & Latitude & Longitude & Period & IGBP & $P(\mathrm{~mm})$ & $T_{\mathrm{A}}\left({ }^{\circ} \mathrm{C}\right)$ & Source \\
\hline BW-Ma1 & Maun-Mopane Woodland & Botswana & $19.93^{\circ} \mathrm{S}$ & $23.57^{\circ} \mathrm{E}$ & $2000-2001$ & WSA & 464 & 22.0 & Fluxnet \\
\hline CG-Euc & Kissoko Eucalyptus Plantation & Congo & $4.79^{\circ} \mathrm{S}$ & $11.98^{\circ} \mathrm{E}$ & 2004-2006 & $\mathrm{EBF}$ & 1274 & 23.5 & CarboAfrica \\
\hline CG-Tch & Tchizalamou & Congo & $4.29^{\circ} \mathrm{S}$ & $11.66^{\circ} \mathrm{E}$ & 2006-2008 & SAV & 1150 & 25.7 & CarboAfrica \\
\hline NE-Waf & Wankama Fallow & Niger & $13.65^{\circ} \mathrm{N}$ & $2.63^{\circ} \mathrm{E}$ & 2006 & $\mathrm{CRO}$ & 519 & 28.5 & AMMA \\
\hline NE-Wam & Wankama Millet & Niger & $13.64^{\circ} \mathrm{N}$ & $2.63^{\circ} \mathrm{E}$ & 2006 & $\mathrm{CRO}$ & 519 & 28.5 & AMMA \\
\hline SD-Dem & Demokeya & Sudan & $13.28^{\circ} \mathrm{N}$ & $30.48^{\circ} \mathrm{E}$ & $2005-2008$ & SAV & 320 & 26.0 & CarboAfrica \\
\hline ZA-Kru & Skukuza & South Africa & $25.02^{\circ} \mathrm{S}$ & $31.50^{\circ} \mathrm{E}$ & $2000-2008$ & SAV & 547 & 21.9 & CarboAfrica \\
\hline ZM-Mon & Mongu & Zambia & $15.44^{\circ} \mathrm{S}$ & $23.25^{\circ} \mathrm{E}$ & $2007-2008$ & $\mathrm{DBF}$ & 945 & 25.0 & CarboAfrica \\
\hline
\end{tabular}

determined by correlating changes in water vapor concentration at the surface and at height measured with hygrometers and a sonic anemometer. The eddy covariance method is considered the most accurate field LE technique. There is on average, however, a $20 \%$ difference between measured turbulent fluxes (sensible heat-H and LE) and $R_{\mathrm{N}}$ for most sites (Wilson et al., 2002). The data used are not corrected for energy balance closure, because many of the energy terms were not available for most of the sites when the data was accessed, as shown in Table 5. Half-hourly (uncorrected) data from the flux towers are used, because the PT-JPL model computes LE from daytime $R_{\mathrm{N}}$ only. Average daily (corrected) data is typically filled using look-up tables (Reichstein et al., 2005) and/or artificial neural networks (Papale and Valentini, 2003), however these data are not available, so persistent data gaps at many of the sites do exist.

\subsection{Statistical analysis}

The analysis is done in three phases: (1) evaluation of the PT-JPL model using station data to determine the appropriateness of the $\mathrm{LE}_{\mathrm{C}}$ component, (2) sensitivity analysis of the PT-JPL model to remote sensing and surface reanalysis forcing and comparison of PT-JPL ground inputs with surface reanalysis inputs to identify sources of error propagation in model hybridization, and (3) development and performance of the hybrid model. The coefficient of determination $\left(R^{2}\right)$ and root mean squared error (RMSE) are the primary metrics used for comparison between observations, models, and inputs. Near infrared and red reflectance are not available from the stations, so NDVI and EVI from MODIS are used instead when evaluating the PT-JPL model and conducting the sensitivity analysis. In the sensitivity analysis, all input variables ( $R_{\mathrm{N}}, T_{\mathrm{MAX}}, q, p, \mathrm{NDVI}$, and $\left.\mathrm{EVI}\right)$ are constrained to mean values except for the test variable (Haan, 2002). The test variable is perturbed 10000 times between $\pm 3 \sigma$. The model output (LE) is regressed against the test input and the slope of the relationship is computed to determine the relative weight of each input to the output. This is considered a conditional case, because only one variable is varied at a time. An unconditional case (not shown) where variables are varied together to look at synergistic effects on modeled LE was also performed, but did not reveal any differences, lending to the strong independence of each model input.

\section{Results}

\subsection{Input and parameter comparison: field data}

The three components $\left(\mathrm{LE}_{\mathrm{C}}, \mathrm{LE}_{\mathrm{S}}\right.$, and $\left.\mathrm{LE}_{\mathrm{I}}\right)$ from the PT-JPL model are plotted, along with observed LE and precipitation in Fig. 1. Transpiration is typically the primary contribution to total $\mathrm{LE}$, however during a rain event, $\mathrm{LE}_{\mathrm{S}}$ and $\mathrm{LE}_{\mathrm{I}}$ can be much more significant. NE-Wam was not included in the figure because it did not significantly deviate from the NE-Waf signal. The magnitude and timing of modeled $\mathrm{LE}_{\mathrm{C}}$ for the five stations with sufficient data to drive the PT-JPL model are captured well at all the sites. Table 6 shows the correlation and error between modeled $\mathrm{LE}_{\mathrm{C}}$ and observed LE for the sites with available data. The highest correlation between modeled $\mathrm{LE}_{\mathrm{C}}$ and observed LE is at the eucalyptus plantation (CG-Euc: included in Fisher et al., 2009). The RMSE and percent error are large, which can be attributed to the significant contribution of $\mathrm{LE}_{S}$ at this humid site. Total LE is overestimated fairly consistently throughout the year, but without reliable observed $\mathrm{LE}_{\mathrm{C}}$ data, it is difficult to discern which component is contributing to this overestimation the most. Persistent data gaps in the ZA-Kru series are due to the frequent turning off of instrumentation to prevent damage from lightning and power surges. Some of the sustained peaks in observed LE at ZA-Kru, notably in the first year, are missed, lending to the lower correlation between modeled $\mathrm{LE}_{\mathrm{C}}$ and observed LE. However, the model does well at capturing the seasonal variability at this relatively drier and more dynamic site. The largest errors between modeled $\mathrm{LE}_{\mathrm{C}}$ and observed LE can be seen at the driest sites (NE-Waf and NE-Wam). The only peak in the time series, corresponding to the primary rain season, is captured, but the magnitude of peak LE from the PT-JPL model is less than $50 \%$ of actual peak LE. In addition, dry season troughs are overestimated. 


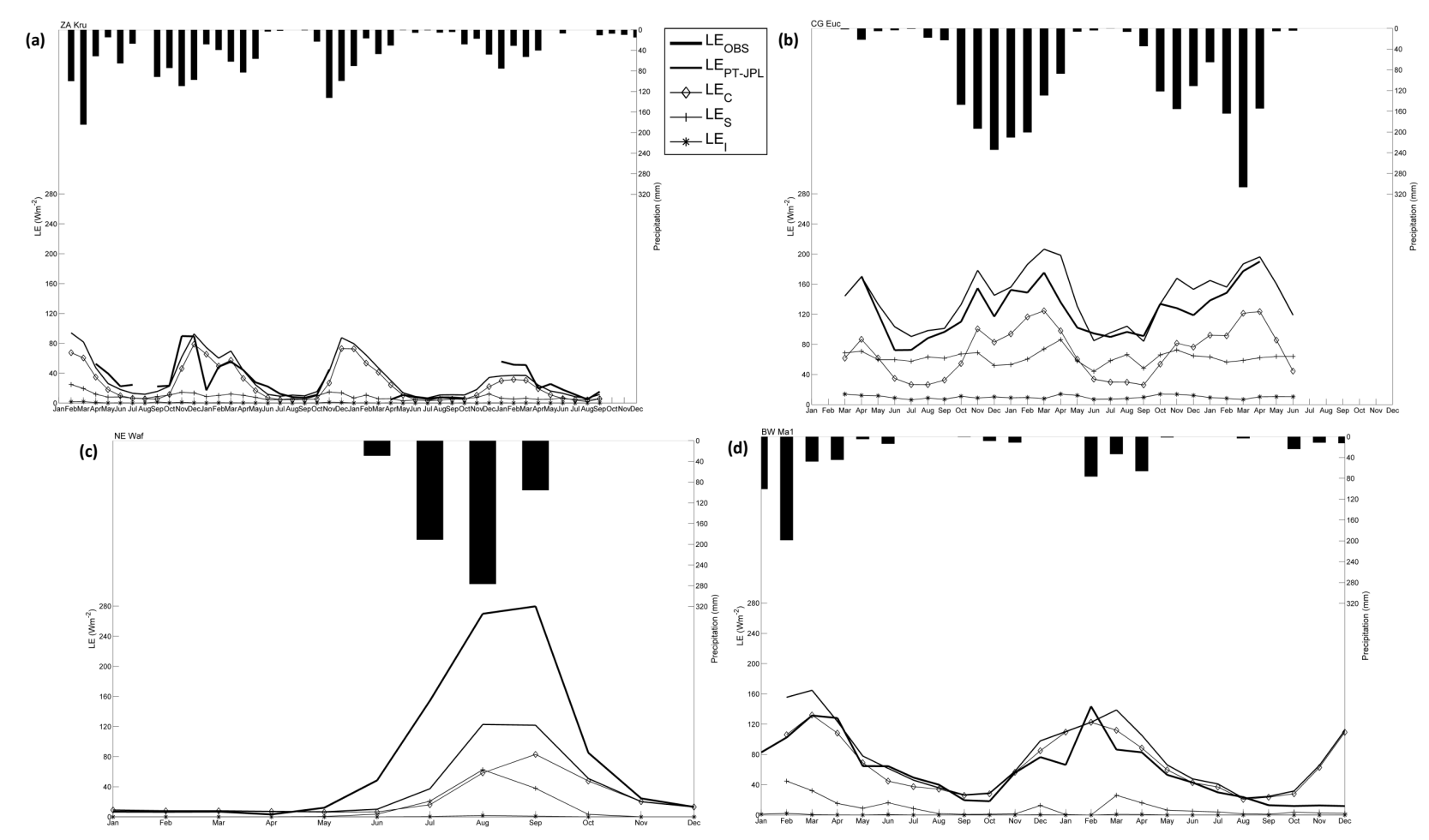

Fig. 1. Monthly observed $\mathrm{LE}_{\mathrm{OBS}}\left(\mathrm{W} \mathrm{m}^{-2}\right)$ and modeled LEPT-JPL $\left(\mathrm{W} \mathrm{m}^{-2}\right)$ plotted on the lower axis and precipitation (mm) plotted on the upper axis using field data from ZA-Kru 2000-2003 (a), CG-Euc 2004-2006 (b), NE-Waf 2006 (c), and BW-Ma1 2000-2001 (d).

Table 5. Data availability $\left(R_{\mathrm{N}}=\right.$ net radiation, $\mathrm{LE}=$ latent heat, $H=$ sensible heat, and $G=$ ground heat) for energy balance closure at eight micrometeorological stations throughout sub-Saharan Africa.

\begin{tabular}{lcccc}
\hline ID & $R_{\mathrm{N}}$ & LE & $H$ & $G$ \\
\hline BW-Ma1 & $\mathrm{x}$ & $\mathrm{x}$ & $\mathrm{x}$ & $\mathrm{x}$ \\
CG-Euc & $\mathrm{x}$ & $\mathrm{x}$ & $\mathrm{x}$ & \\
CG-Tch & & $\mathrm{x}$ & $\mathrm{x}$ & \\
NE-WaF & $\mathrm{x}$ & $\mathrm{x}$ & & \\
NE-WaM & $\mathrm{x}$ & $\mathrm{x}$ & & \\
SD-Dem & & $\mathrm{x}$ & $\mathrm{x}$ & \\
ZA-Kru & $\mathrm{x}$ & $\mathrm{x}$ & $\mathrm{x}$ & $\mathrm{x}$ \\
ZM-Mon & & $\mathrm{x}$ & $\mathrm{x}$ & \\
\hline
\end{tabular}

\subsection{Sensitivity analysis and GLDAS forcing errors}

The relative strength of each input variable to PT-JPL LE model variance is shown in Table 7 for ZA-Kru. No change in sensitivity is observed across the sites. The slope and intercept are generated from linear fits of model output data to input data in normalized space. The slope of the fit therefore represents the average expected increase in LE due to a standard deviation increase in the test variable. PT-JPL is most sensitive to EVI and $q$, because these variables have the largest slopes, while the model is least sensitive to $p$. Specific humidity and $p$ are used primarily in the $f_{\mathrm{WET}}$ component
( $L E_{S}$ and $\left.L E_{I}\right)$. Similarly, EVI is used in each component for discretization, but its contribution is largest for $\mathrm{LE}_{\mathrm{C}}$. After EVI and $q$, PT-JPL is most sensitive to $R_{\mathrm{N}}$, which is common to all three components of LE. Increases in NDVI and $T$ act to suppress LE, as indicated by the negative slopes. NDVI in the PT-JPL model is in the denominator of $f_{\mathrm{G}}$, since it is used to indicate overall absorption of incoming radiation by the canopy. As NDVI increases, $f_{\mathrm{G}}$ decreases, since NDVI tends to be more variable than EVI. Temperature is explicitly handled in the plant temperature constraint function $\left(\mathrm{LE}_{\mathrm{C}}\right)$ - increases in temperature above the optimum temperature leads to increases in this constraint and lower LE.

The monthly aggregated GLDAS data used to drive the PT-JPL model $\left(R_{\mathrm{N}}, T_{\mathrm{MAX}}, q\right.$, and $\left.p\right)$ are plotted against observed data for ZA-Kru in Fig. 2. Table 8 summarizes the results for all of the stations with sufficient field data for the comparison. Some of the relationships are clearly non-linear, however statistics from a linear fit are chosen for comparison purposes between inputs and across sites. It is expected that GLDAS $p$ and $q$ data correlates well with observed RH. Observed $q$ and $p$ are not used for direct comparison, because these data are not available for many of the sites. GLDAS $R_{\mathrm{N}}$, $T$, and $q$ showed good agreement with observed data. Temperature from the GLDAS dataset, which is used exclusively in the $\mathrm{LE}_{\mathrm{C}}$ component, consistently shows high correlations across all the sites. Net radiation, which is the third most sensitive input, on the other hand, shows poor correlations across 
Table 6. Summary results from the comparison of observed monthly LE and PT-JPL LE .

\begin{tabular}{lr}
\hline Station ID & LE $_{\mathrm{C}}$ \\
\hline BW-Ma1 & \\
$R^{2}$ & 0.61 \\
RMSE & 26.96 \\
$\%$ error & 28.49 \\
\hline CG-Euc & \\
$R^{2}$ & 0.86 \\
RMSE & 56.09 \\
$\%$ error & 43.66 \\
\hline NE-Waf & \\
$R^{2}$ & 0.78 \\
RMSE & 93.91 \\
$\%$ error & 70.76 \\
\hline ZA-Kru & \\
$R^{2}$ & 0.61 \\
RMSE & 16.31 \\
$\%$ error & 43.55 \\
\hline
\end{tabular}

most of the sites. Two sites (CG-Euc and ZA-Kru) show good correlations for $R_{\mathrm{N}}$, but also large bias. Specific humidity is the second best predicted input. It is also the most sensitive PT-JPL model input after EVI, though not used extensively in the $\mathrm{LE}_{\mathrm{C}}$ component. The inverse relationship between $p$ and RH is present, but obscured by outliers above $98.0 \mathrm{kPa}$ (Fig. 2d). The outliers are from the first year of the reanalysis when the GDAS reanalysis fields are used exclusively. BWMa1 is the only other site that showed such a relationship.

\subsection{Hybrid model}

Time series of observed LE and modeled LE using PT-JPL, GNOAH, and the combined model (PT-JPL LE $\mathrm{C}_{\mathrm{C}}+\mathrm{GNOAH}$ $\mathrm{LE}_{\mathrm{I}, \mathrm{S}}$ ) for six of the eight stations are shown in Fig. 3. Table 9 includes goodness-of-fit statistics for six of the eight stations: ZM-Mon and NE-Wam are omitted, because the former had less than one year of data and the latter showed no noticeable difference from NE-Waf. Two of the stations (BW-Ma1 and CG-Tch) showed obvious bad (flat) LE data at the beginning and end of the time series when the sensors were just coming online or not being monitored, so statistics are computed after these points were omitted. The last month of CG-Tch was omitted as well, because the site was burned in July 2008. Grass was absent after the burn and the soil humidity was less than $2 \%$ by volume, so $H$ is the dominant energy flux.

The combined model outperforms the GNOAH model for the majority of sites and equally as well for the remaining sites. The greatest improvements are made between the PT-JPL and hybrid model, particularly in the reduction in RMSE. These improvements are greatest at the sites with dense vegetation (CG-Euc and BW-Ma1). At these sites, the
Table 7. The slope $\left(B_{1}\right)$ and intercept $\left(B_{0}\right)$ of a linear fit of modeled LE using the mean for all input data and 10000 perturbations of one test input variable $(i)$ versus the test input variable in standard space.

\begin{tabular}{lrr}
\hline$i$ & $B_{1}\left(\mathrm{~W} \mathrm{~m}^{-2}\right)$ & $B_{0}\left(\mathrm{~W} \mathrm{~m}^{-2}\right)$ \\
\hline EVI & 29.61 & 92.61 \\
NDVI & -9.88 & 74.63 \\
$R_{\mathrm{N}}\left(\mathrm{W} \mathrm{m}^{-2}\right)$ & 16.77 & 74.63 \\
\hline$p(\mathrm{kPa})$ & 0.73 & 78.78 \\
$q\left(\mathrm{~kg} \mathrm{~kg}{ }^{-1}\right)$ & 24.65 & 85.81 \\
$T\left({ }^{\circ} \mathrm{C}\right)$ & -16.18 & 78.78 \\
\hline
\end{tabular}

Table 8. Summary statistics of PT-JPL model inputs from field data versus Noah reanalysis data. $B_{1}$ and $B_{0}$ are the slope and intercept of the linear fit and $N$ is the number of monthly samples. The statistics for Noah pressure and specific humidity were derived using relative humidity from the field.

\begin{tabular}{|c|c|c|c|c|}
\hline Station ID & $R_{\mathrm{N}}\left(\mathrm{W} \mathrm{m}^{-2}\right)$ & $T\left({ }^{\circ} \mathrm{C}\right)$ & $q\left(\mathrm{~kg} \mathrm{~kg}^{-1}\right)$ & $p(\mathrm{kPa})$ \\
\hline \multicolumn{5}{|c|}{ BW-Ma1 $(N=23)$} \\
\hline $\mathrm{R}$ & 0.06 & 0.85 & 0.50 & -0.11 \\
\hline$B_{1}$ & 0.10 & 0.96 & 0.02 & -0.33 \\
\hline$B_{0}$ & 211.78 & 0.19 & 0.0067 & 91.17 \\
\hline RMSE & 88.71 & 2.20 & & \\
\hline \multicolumn{5}{|c|}{ CG-Euc $(N=30)$} \\
\hline $\mathrm{R}$ & 0.72 & 0.72 & -0.46 & 0.52 \\
\hline$B_{1}$ & 0.23 & 0.62 & -0.04 & 4.02 \\
\hline$B_{0}$ & 169.17 & 11.24 & 0.04 & 97.92 \\
\hline RMSE & 42.99 & 1.61 & & \\
\hline \multicolumn{5}{|c|}{ NE-Waf $(N=12)$} \\
\hline $\mathrm{R}$ & -0.38 & 0.97 & 0.94 & 0.29 \\
\hline$B_{1}$ & -0.18 & 1.07 & 0.03 & 0.26 \\
\hline$B_{0}$ & 276.28 & -0.90 & 0.002 & 98.23 \\
\hline RMSE & 81.80 & 1.98 & & \\
\hline \multicolumn{5}{|c|}{$\mathrm{NE}-\operatorname{Wam}(N=11)$} \\
\hline $\mathrm{R}$ & -0.17 & 0.93 & 0.98 & 0.27 \\
\hline$B_{1}$ & 0.0012 & 1.13 & 0.03 & 0.23 \\
\hline$B_{0}$ & 243.81 & -2.28 & 0.0013 & 98.12 \\
\hline RMSE & 109.52 & 2.71 & & \\
\hline \multicolumn{5}{|c|}{$\mathrm{ZA}-\mathrm{Kru}(N=44)$} \\
\hline $\mathrm{R}$ & 0.88 & 0.70 & 0.71 & 0.06 \\
\hline$B_{1}$ & 1.29 & 0.44 & 0.02 & -0.58 \\
\hline$B_{0}$ & 83.43 & 13.94 & 0.0029 & 97.11 \\
\hline RMSE & 118.46 & 2.33 & & \\
\hline
\end{tabular}

hybrid model tends to underestimate the peaks and overestimate the troughs. At the driest sites (NE-Wam, NE-Waf, and SD-Dem), all three models grossly underestimate peak LE, however the combined model performs the best. The major limitation of GNOAH, namely lack of a time-varying vegetation component, is reflected in the time series at the ZA-Kru site. The smooth LE signal produced by the GNOAH model does not capture the interannual variability of this semi-arid site. The PT-JPL model represents the other extreme, as it overestimates the variability in observed LE. The combined model is a compromise between the two. All three models tend to perform poorest for CG-Tch, missing the peak in 2007 and the secondary peak in 2008 . 

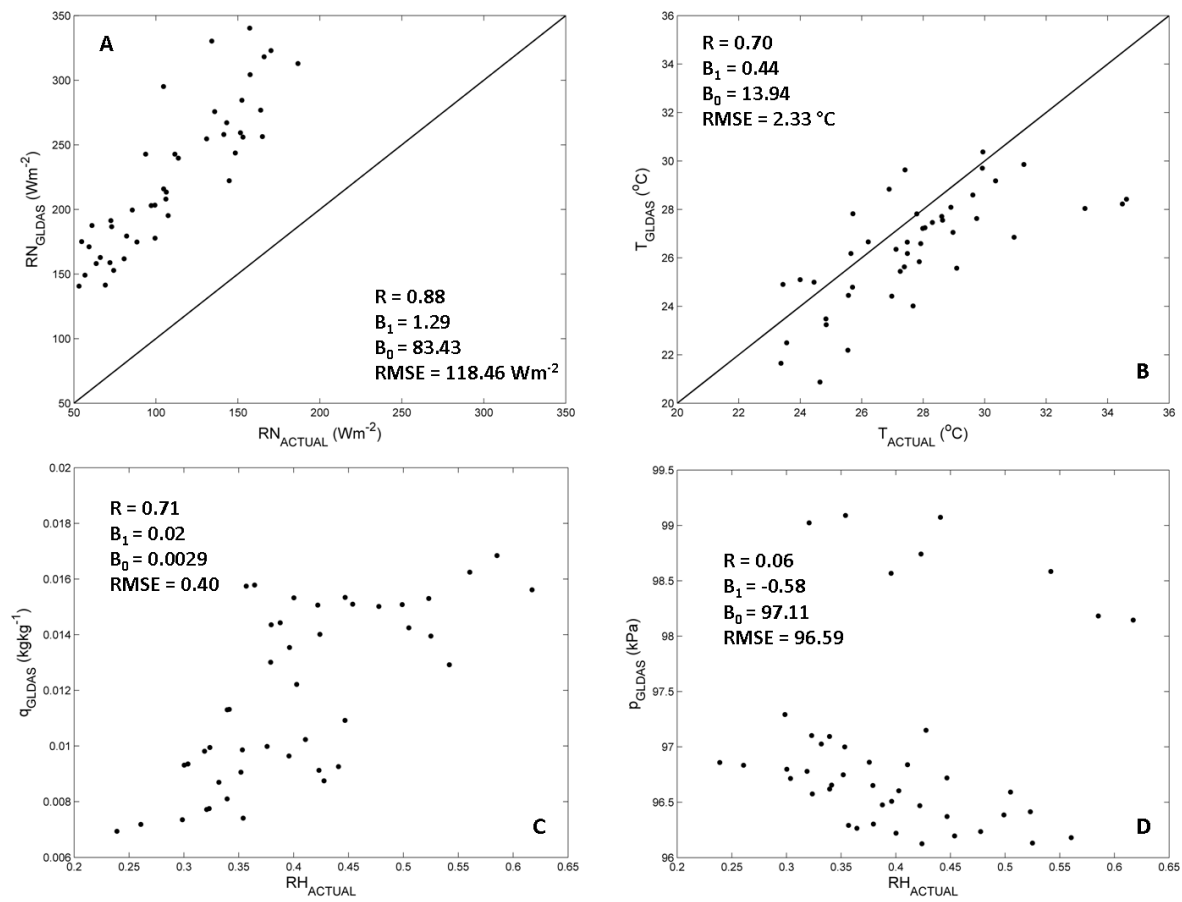

Fig. 2. Plot of Berkeley model inputs from monthly field data versus Noah reanalysis data for ZA-Kru. Net radiation (a), maximum daily temperature (b), specific humidity (c), and surface pressure (d).

Table 9. Summary results from the comparison of observed monthly LE to the PT-JPL, Noah, and hybrid (PT-JPL $\left.\mathrm{LE}_{\mathrm{C}}+\mathrm{GNOAH} \mathrm{LE}_{(\mathrm{I}, \mathrm{S})}\right)$.

\begin{tabular}{llll}
\hline Station ID & PT-JPL & GNOAH & Hybrid \\
\hline BW-Ma1 & 0.70 & 0.75 & 0.76 \\
$R^{2}$ & 30.03 & 23.58 & 22.06 \\
RMSE & 32.23 & 27.79 & 24.99 \\
$\%$ error & & & \\
\hline CG-Euc & 0.53 & 0.71 & 0.80 \\
$R^{2}$ & 42.15 & 67.89 & 25.31 \\
RMSE & 29.85 & 53.10 & 16.44 \\
$\%$ error & & & \\
\hline CG-Tch & 0.34 & 0.39 & 0.38 \\
$R^{2}$ & 101.34 & 29.13 & 65.27 \\
RMSE & 163.85 & 40.25 & 92.82 \\
$\%$ error & & & \\
\hline NE-Waf & 0.82 & 0.91 & 0.91 \\
$R^{2}$ & 85.71 & 94.97 & 74.38 \\
RMSE & 67.82 & 71.20 & 56.02 \\
$\%$ error & & & \\
\hline SD-Dem & 0.55 & 0.53 & 0.60 \\
$R^{2}$ & 58.69 & 67.93 & 51.56 \\
RMSE & 54.84 & 65.86 & 45.00 \\
$\%$ error & & & \\
\hline ZA-Kru & 0.44 & 0.45 & 0.55 \\
$R^{2}$ & 48.40 & 34.80 & 36.00 \\
RMSE & 87.70 & 59.80 & 56.67 \\
$\%$ error & & & \\
\hline & & & \\
\hline & & & \\
\hline & & & \\
\hline & & & \\
\hline & & & \\
\hline & & & \\
\hline & & & \\
\hline
\end{tabular}

\section{Discussion}

The study represents an initial attempt to use a suite of new flux tower data in sub-Saharan Africa to improve ET estimation using remote sensing and surface climate reanalysis data for regular near real-time continental scale monitoring. The integration of the evaporation components from GNOAH with the PT-JPL transpiration component further improves the correlations and reduces the RMSE for both humid and semi-arid sites compared to the models before hybridization. The fractional total vegetation cover of GNOAH is the single most important variable controlling transpiration. This is consistent with other findings that showed LAI was a strong control on the ratio of ET/PET at savanna sites (Williams et al., 2009). The use of climatology to derive this component often suffers in semi-arid climates where variability in vegetation can be high. This is most apparent at the drier sites, where GNOAH shows low interannual variability. The introduction of a time-varying component dramatically improves the correlation between observed and modeled LE. The PTJPL and GNOAH model use two different satellite sensors (AVHRR and MODIS) to determine vegetation indices, and this undoubtedly plays a role in the results, which should be considered along with other products in the future.

The greatest improvements in modeled LE using the combined model are at the sites with dense vegetation, while only modest improvements can be seen at the drier sites. The predictability of LE for the various vegetation using the 

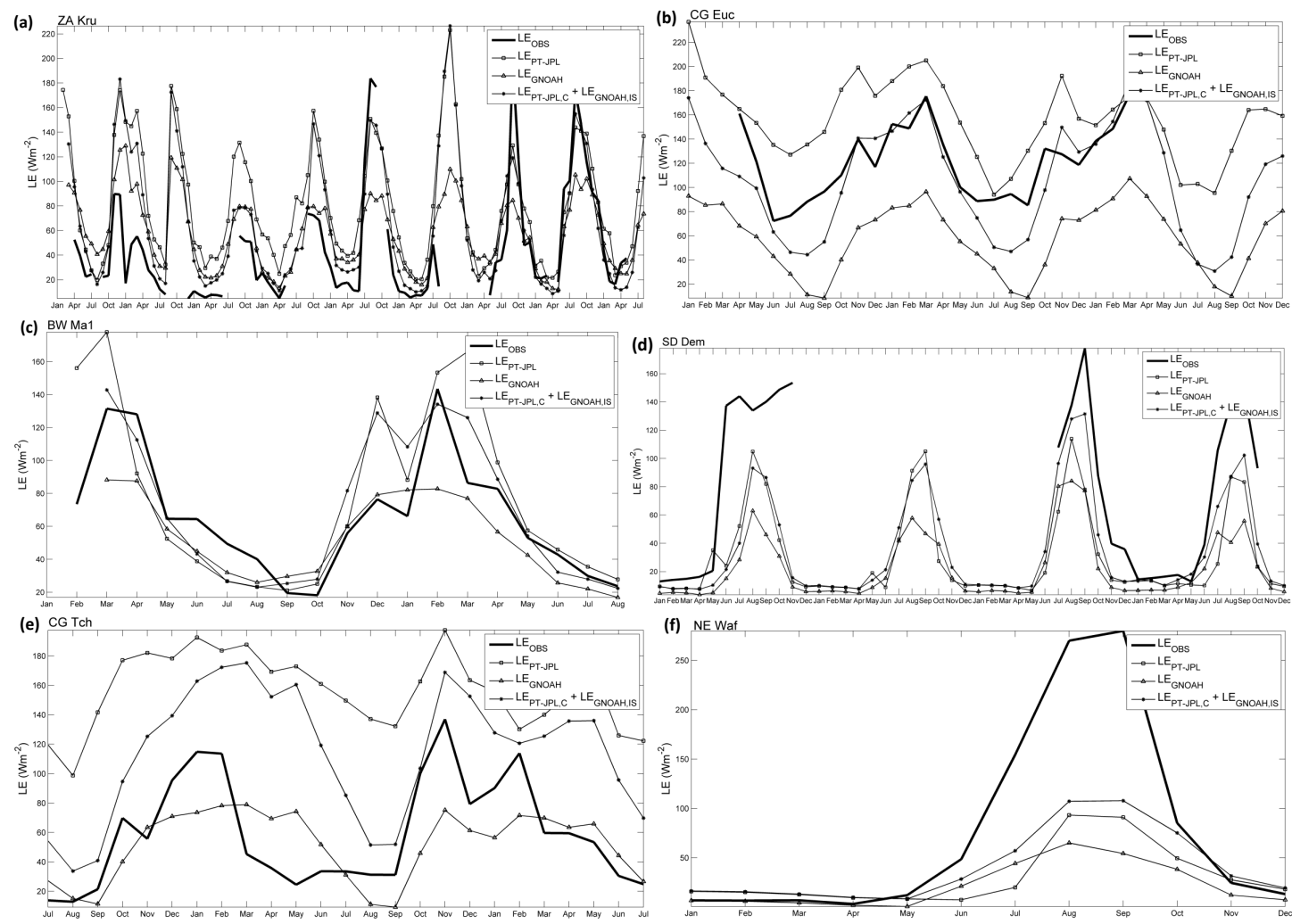

Fig. 3. Monthly time series of available LE data (-) plotted with Fisher LE ( $\square)$, Noah LE ( $\Delta$ ), and Fisher $\operatorname{LE}_{\mathrm{C}}+\mathrm{GNoah}_{\mathrm{LE}}(\mathrm{I}, \mathrm{S})$ for ZA-Kru (a), CG-Euc (b), BW-Ma1 (c), SD-Dem (d), CG-Tch (e), and NE-Waf (f).

combined model can be attributed in part to light and water limitation (Mu et al., 2007b). Dense vegetation in the wet tropics is light limited because soil is sufficiently wetted throughout the year, so one would expect that LE is driven primarily by $R_{\mathrm{N}}$. Sparse vegetation in the dry tropics on the other hand is water limited (humidity driven), because light is sufficient to maximize stomatal conductance throughout the year and plants close their stomata in response to dry conditions to conserve water and avoid stress. The CG-Euc observed time series was one of the longest available. The high correlation between surface reanalysis and observed $R_{\mathrm{N}}$ could therefore be inflated, due to the presence of outliers reflected in the large bias. Given the low sensitivity of the PT-JPL model to $R_{\mathrm{N}}$ compared to EVI and $q$ at this site, however, the bias appears to have little impact on the hybrid model. Similar model dependence on surface temperature and the high correlation, low bias, and inverse sensitivity of the reanalysis temperature could be offsetting the effects of reanalysis $R_{\mathrm{N}}$, however, the unconditional sensitivity analysis revealed no strong interdependencies. The correlation between specific humidity from the reanalysis and observed relative humidity are highest at the two driest sites (NE-Waf and NE-Wam) and this lends to modest and less significant improvements in model performance compared to the humid sites. Although PT-JPL is least sensitive to pressure, erroneous values can lead to a $16 \%$ difference between the PT-JPL and the hybrid model. This is most apparent in 2000 at ZA-Kru, where pressure values from the GDAS fields were several kPA higher than for other years. Improvements in GLDAS reanalysis will undoubtedly reduce the variability in future studies that use the PT-JPL model driven by surface reanalysis. Vapor pressure could be used, for example, from a study that determined it from MODIS estimates of dew point temperature in Korea (Ryu et al., 2008).

The large discrepancy of the models from peak ET at the driest sites could be due to several factors. Although energy balance closure problems are typically associated with errors in measuring turbulent fluxes, measurement error in $R_{\mathrm{N}}$ remains a possibility. Ramier et al. (2009) reported only modest daily average energy balance biases of $14.2 \mathrm{~W} \mathrm{~m}^{-2}$ for NE-Wam, which does not account for the model underestimation of peak LE with observed input data by more than $30 \%$. Another possibility in LE underestimates at NE-Wam and NE-Waf could be the result of unexpectedly low average daytime $R_{\mathrm{N}}$ during the wet season that appear to result from large increases in longwave outgoing minus longwave incoming $(\Delta \mathrm{LW})$ near sunset. The increase in absolute $\Delta \mathrm{LW}$ can be attributed to increases in soil moisture (lower sensible heat and longwave outgoing) and cloud cover (increased longwave incoming) that is typical during the wet season 
(Ramier et al., 2009). These factors could lead to a drop in LE of nearly $17 \mathrm{~W} \mathrm{~m}^{-2}$, assuming a one standard deviation drop in $R_{\mathrm{N}}$ from the sensitivity analysis, which still does not account for the underestimation of LE. It is expected that the large positive bias from the reanalysis data would act to improve the correlations at the driest sites, unless offset by other factors. The largest contributor to the underestimation of LE, therefore, is most likely due to the resolution of EVI and NDVI data and strong dependence of PT-JPL LE $\mathrm{C}_{\mathrm{C}}$ on EVI: a $0.05^{\circ}$ resolution pixel is too coarse to adequately capture the dynamics of a sparse canopy. Even with gross underestimation of $R_{\mathrm{N}}$ and EVI, the comparison of observed data with PT-JPL reveals that LE remains difficult to model in the very driest areas. Improvements to PT-JPL LE $E_{C}$, such as the use of an EVI ratio to formulate $f_{\mathrm{C}}$ as in Mu et al. (2007b), spectral unmixing, calibration of $S$ in NOAH for semi-arid regions, or the use of different forcing data when the LIS becomes more operationally available, should be addressed in future studies to reduce uncertainties in semi-arid regions.

It is difficult to make a more detailed assessment on the performance of the hybrid model, because the comparison is done using limited flux tower data. Firstly, the satellite and surface climate reanalysis scale data in this paper is assumed to capture the average of a grid cell corresponding to the station used for validation. This assumption can be problematic and scaling flux tower data to coarser scales therefore remains an active area of research. The greatest challenge is finding flux towers that lie within homogenous and flat terrain corresponding to the spatial resolution of satellite or surface reanalysis data. If the fetch of the flux tower includes heterogeneous and/or rough terrain, eddy formation can be highly variable and may not be consistent with the areal average (Baldocchi et al., 1988). A possible solution could be to evaluate these models using several flux towers within a grid cell, representing the various land cover types and taking a weighted average to compare with coarser scale data. Secondly, the data for many of the flux towers is incomplete, leading to potential uncertainties with monthly aggregation. Even with these inconsistencies, it is clear that all three models underestimate dry area peaks (GNOAH the most with low interannual variability) and in humid areas where data is more consistent, the hybrid model shows the highest correlation and lowest bias with observed data. Finally, the model could be further validated using larger scale surrogates of ET. In one example, the hybrid model is used to develop a crop stress index that successfully tracked multi-year district-level crop yield and identified historical, insecure food hotspots in Kenya (Marshall et al., 2012b). In another example (Marshall et al., 2012a), runoff data is combined with precipitation to validate the model in an annual water balance. Runoff data is extremely limited after the year 2000 for basins in subSaharan Africa, so GNOAH at 1.0 degree resolution and the Land Long Term Data Record AVHRR vegetation indices (http://ltdr.nascom.nasa.gov/cgi-bin/ltdr/ltdrPage.cgi), which extends back before 2000, are used instead.

\section{Conclusions}

The need to understand energy and water fluxes in datasparse regions of the world is an important field of research that demands the use of cost-effective and efficient modeling approaches. In this paper, a new approach to modeling ET, an important energy and moisture flux, has been introduced. For the first time, an ET model has been evaluated using the eddy covariance technique over areas representing major land-cover classes in sub-Saharan Africa. The paper highlights many of the obstacles and limitations of such an analysis. Even with these shortcomings, the substitution of transpiration from an LSM that uses climatological average NDVI with a direct remote sensing-based transpiration model that uses a time series of NDVI and EVI effectively leverages the information on vegetation phenology with remote sensing observations, while retaining details on the soil physics controlling surface fluxes.

Acknowledgements. This work was primarily supported by the US Agency for International Development through a US Geological Survey cooperative agreement (04HQAG0001) and National Aeronautics and Space Administration Precipitation grant (NNX07AG26G). The eddy covariance data was acquired by the Fluxnet community via the financial support of CarboEuropeIP, FAO-GTOS-TCO, iLEAPS, Max Planck Institute for Biogeochemistry, National Science Foundation, University of Tuscia, Université Laval and Environment Canada and US Department of Energy and the database development and technical support from Berkeley Water Center, Lawrence Berkeley National Laboratory, Microsoft Research eScience, Oak Ridge National Laboratory, University of California - Berkeley, University of Virginia. The authors would also like to acknowledge the contribution of eddy covariance data through AMMA, which is based on a French initiative to build an international scientific group, and was funded by a large number of agencies, especially from France, the UK, the US and Africa, as well as by the European Community's Sixth Framework Research Programme.

Edited by: C. de Michele

\section{References}

Anderson, M. C., Normana, J. M., Diak, G. R., Kustas, W. P., and Mecikalski, J. R.: A Two-Source Time-Integrated Model for Estimating Surface Fluxes Using Thermal Infrared Remote Sensing, Remote Sens. Environ., 60, 195-216, 1997.

Anderson, M. C., Norman, J. M., Meyers, T. P., and Diak, G. R.: An analytical model for estimating canopy transpiration and carbon assimilation fluxes based on canopy light-use efficiency, Agr. Forest Meteorol., 101, 265-289, 2000.

Baldocchi, D. D., Hincks, B. B., and Meyers, T. P.: Measuring Biosphere-Atmosphere Exchanges of Biologically Related Gases with Micrometeorological Methods, Ecology, 69, 13311340, 1988.

Bastiaanssen, W. G. M., Menentia, M., Feddes, R. A., and Holtslag, A. A. M.: A remote sensing surface energy balance algorithm for 
land (SEBAL): 1. Formulation, J. Hydrol., 212-213, 198-212, 1998.

Betts, A. K., Chen, F., Mitchell, K. E., and Janjić, Z. I.: Assessment of the Land Surface and Boundary Layer Models in Two Operational Versions of the NCEP Eta Model Using FIFE Data, Mon. Weather Rev., 125, 2896-2916, 1997.

Boni, G., Entekhabi, D., and Castelli, F.: Land Data Assimilation with Satellite Measurements for the Estimation of Surface Energy Balance Components and Surface Control on Evaporation, Water Resour. Res., 37, 1713-1722, 2001.

Boone, A., De Rosnay, P., Balsamo, G., Beljaars, A., Chopin, F., Decharme, B., Delire, C., Ducharne, A., Gascoin, S., Guichard, F., Gusev, Y., Harris, P., Jarlan, L., Kergoat, L., Mougin, E., Nasonova, O., Norgaard, A., Orgeval, T., Ottlé, C., PoccardLeclercq, I., Polcher, J., Sandholt, I., Saux-Picart, S., Taylor, C. M., and Xue, Y.: The AMMA Land Surface Model Intercomparison Project (ALMIP), B. Am. Meteorol. Soc., 90, 1865-1880, 2009.

Bouchet, R. J.: Evapotranspiration reelle et potentielle, signification climatique, International Association of Hydrological Sciences 62, 134-142, 1963.

Chen, F. and Dudhia, J.: Coupling an Advanced Land SurfaceHydrology Model with the Penn State-NCAR MM5 Modeling System. Part I: Model Implementation and Sensitivity, Mon. Weather Rev., 129, 569-585, 2001.

Chen, F., Mitchell, K., Schaake, J., Xue, Y., Pan, H., Koren, V., Duan, Q. Y., Ek, M., and Betts, A.: Modeling of land surface evaporation by four schemes and comparison with FIFE observations, J. Geophys. Res., 101, 2896-2916, 1996.

Chen, Y., Randerson, J. T., van der Werf, G. R., Morton, D. C., $\mathrm{Mu}$, M., and Kasibhatla, P. S.: Nitrogen deposition in tropical forests from savanna and deforestation fires, Glob. Change Biol., 16, 2024-2038, 2010.

DehghaniSanij, H., Yamamoto, T., and Rasiah, V.: Assessment of evapotranspiration estimation models for use in semi-arid environments, Agr. Water Manage., 64, 91-106, 2004.

Diak, G. R., Mecikalski, J. R., Anderson, M. C., Norman, J. M., Kustas, W. P., Torn, R. D., and Dewolf, R. L.: Estimating Land Surface Energy Budgets from Space: Review and Current Efforts at the University of Wisconsin-Madison and USDS-ARS, B. Am. Meteorol. Soc., 85, 65-78, 2004.

FAOSTAT: FAO Statistical Database, Food and Agriculture Organization, United Nations, Rome, Italy, 2010.

Fisher, J. B., Tu, K. P., and Baldocchi, D. D.: Global estimates of the land-atmosphere water flux based on monthly AVHRR and ISLSCP-II data, validated at 16 FLUXNET sites, Remote Sens. Environ., 112, 901-919, 2008.

Fisher, J. B., Malhi, Y., Bonal, D., Da Rocha, H. R., De Araujo, A. C., Gamo, M., Goulden, M. L., Hirano, T., Huete, A. R., Kondo, H., Kumagai, T. O., Loescher, H. W., Miller, S., Nobre, A. D., Nouvellon, Y., Oberbauer, S. F., Panuthai, S., Roupsard, O., Saleska, S., Tanaka, K., Tanaka, N., Tu, K. P., and von Randow, C.: The land-atmosphere water flux in the tropics, Glob. Change Biol., 15, 2694-2714, 2009.

Gao, X., Huete, A. R., Ni, W., and Miura, T.: Optical-Biophysical Relationships of Vegetation Spectra without Background Contamination, Remote Sens. Environ., 74, 609-620, 2000.

Gentine, P., Entekhabi, D., Chehbouni, A., Boulet, G., and Duchemin, B.: The Diurnal Behavior of Evaporative Fraction in the Soil-Vegetation-Atmospheric, J. Hydrometeorol., 12, 15301546, 2011.

Glenn, E. P., Huete, A. R., Nagler, P. L., Hirschboeck, K. K., and Brown, P.: Integrating Remote Sensing and Ground Methods to Estimate Evapotranspiration, Cr. Rev. Plant Sci., 26, 139-168, 2007.

Gutman, G., and Ignatov, A.: The derivation of the green vegetation fraction from NOAA/AVHRR data for use in numerical weather prediction models, Int. J. Remote Sens., 19, 1533-1543, 1998.

Haan, C. T.: Statistical Methods in Hydrology, 2nd Edn., 496 pp., Iowa State Press, Ames, IA, 2002.

Hartmann, D. L.: Global Physical Climatology, 411 pp., Academic Press, San Diego, 1994.

Hogue, T. S., Bastidas, L., Gupta, H., Sorooshian, S., Mitchell, K., and Emmerich, W.: Evaluation and Transferability of the Noah Land Surface Model in Semiarid Environments, J. Hydrometeorol., 6, 68-84, 2005.

Huete, A., Didan, K., Miura, T., Rodriguez, E. P., Gao, X., and Ferreira, L. G.: Overview of the radiometric and biophysical performance of the MODIS vegetation indices, Remote Sens. Environ., 83, 195-213, 2002.

Jacquemin, B. and Noilhan, J.: Sensitivity study and validation of a land surface parameterization using the HAPEX-MOBILHY data set, Bound.-Lay. Meteorol., 52, 93-134, 1990.

Jiménez, C., Prigent, C., Mueller, B., Seneviratne, S. I., McCabe, M. F., Wood, E. F., Rossow, W. B., Balsamo, G., Betts, A. K., Dirmeyer, P. A., Fisher, J. B., Jung, M., Kanamitsu, M., Reichle, R. H., Reichstein, M., Rodell, M., Sheffield, J., Tu, K., and Wang, K.: Global intercomparison of 12 land surface heat flux estimates, J. Geophys. Res., 116, D02102, doi:201110.1029/2010JD014545, 2011.

June, T., Evans, J. R., and Farquhar, G. D.: A simple new equation for the reversible temperature dependence of photosynthetic electron transport: a study on soybean leaf, Funct. Plant Biol., 31, 275-283, 2004.

Kalma, J. D., McVicar, T. R., and McCabe, M. F.: Estimating Land Surface Evaporation: A Review of Methods Using Remotely Sensed Surface Temperature Data, Surv. Geophys., 29, 421-469, 2008.

Kelliher, F. M., Leuning, R., Raupach, M. R., and Schulze, E.-D.: Maximum conductances for evaporation from global vegetation types, Agr. Forest Meteorol., 73, 1-16, 1995.

Kite, G. W. and Droogers, P.: Comparing evapotranspiration estimates from satellites, hydrological models and field data, J. Hydrol., 229, 3-18, 2000.

Kumar, S. V., Peters-Lidard, C. D., Tian, Y., Houser, P. R., Geiger, J., Olden, S., Lighty, L., Eastman, J. L., Doty, B., Dirmeyer, P., Adams, J., Mitchell, K., Wood, E. F., and Sheffield, J.: Land Information System - An interoperable framework for high resolution land surface modeling, Environ. Model. Softw., 21, 1402 1415, 2006.

Leuning, R., Zhang, Y. Q., Rajaud, A., Cleugh, H., and Tu, K.: A simple surface conductance model to estimate regional evaporation using MODIS leaf area index and the Penman-Monteith equation, Water Resour. Res., 44, W10419, doi:1029/2007WR006562, 2008.

Mahfouf, J. F. and Noilhan, J.: Comparative Study of Various Formulations of Evaporations from Bare Soil Using In Situ Data, J. Appl. Meteorol., 30, 1354-1365, 1991. 
Mahrt, L. and Ek, M.: The Influence of Atmospheric Stability on Potential Evaporation, J. Appl. Meteorol., 23, 222-234, 1984.

Marshall, M. T., Funk, C., and Michaelsen, J.: Examining Evapotranspiration Trends in Africa, Clim. Dynam., 38, 1849-1865, doi:10.1007/s00382-012-1299-y, 2012a.

Marshall, M. T., Funk, C., and Michaelsen, J.: Agricultural Drought Monitoring in Kenya Using Evapotranspiration Derived from Remote Sensing and Reanalysis Data, in Remote Sensing of Drought: Innovative Monitoring Approaches, edited by: Anderson, M. and Verdin, J., Taylor and Francis, London, UK, 2012b.

Mu, Q., Zhao, M., Heinsch, F. A., Liu, M., Tian, H., and Running, S. W.: Evaluating water stress controls on primary production in biogeochemical and remote sensing based models, J. Geophys. Res., 112, G01012, doi:10.1029/2006JG000179, 2007a.

Mu, Q., Heinsch, F. A., Zhao, M., and Running, S. W.: Development of a global evapotranspiration algorithm based on MODIS and global meteorology data, Remote Sens. Environ., 111, 519-536, $2007 b$.

Mueller, B., Seneviratne, S. I., Jimenez, C., Corti, T., Hirschi, M., Balsamo, G., Ciais, P., Dirmeyer, P., Fisher, J. B., Guo, Z., Jung, M., Maignan, F., McCabe, M. F., Reichle, R., Reichstein, M., Rodell, M., Sheffield, J., Teuling, A. J., Wang, K., Wood, E. F., and Zhang, Y.: Evaluation of global observations-based evapotranspiration datasets and IPCC AR4 simulations, Geophys. Res. Lett., 38, L06402, doi:10.1029/2010GL046230, 2011.

Nishida, K., Nemani, R. R., Glassy, J. M., and Running, S. W.: Development of an evapotranspiration index from Aqua/MODIS for monitoring surface moisture status, IEEE T. Geosci. Remote, 41, 493-501, 2003.

Olioso, A., Chauki, H., Courault, D., and Wigneron, J.-P.: Estimation of Evapotranspiration and Photosynthesis by Assimilation of Remote Sensing Data into SVAT Models, Remote Sens. Environ., 68, 341-356, 1999.

Palmer, A. R. and Yunusa, I. A. M.: Biomass production, evapotranspiration and water use efficiency of arid rangelands in the Northern Cape, South Africa, J. Arid Environ., 11, 1223-1227, 2011.

Pan, H. L. and Mahrt, L.: Interaction between soil hydrology and boundary-layer development, Bound.-Lay. Meteorol., 38, 185202, 1987.

Papale, D. and Valentini, R.: A new assessment of European forests carbon exchanges by eddy fluxes and artificial neural network spatialization, Glob. Change Biol., 9, 525-535, 2003.

Penman, H. L.: Natural Evaporation from Open Water, Bare Soil and Grass, P. R. Soc. Lond. A-Mat., 193, 120-145, 1948.

Priestley, C. H. B. and Taylor, R. J.: On the Assessment of Surface Heat Flux and Evaporation Using Large-Scale Parameters, Mon. Weather Rev., 100, 81-92, 1972.

Ramier, D., Boulain, N., Cappelaere, B., Timouk, F., Rabanit, M., Lloyd, C. R., Boubkraoui, S., Métayer, F., Descroix, L., and Wawrzyniak, V.: Towards an understanding of coupled physical and biological processes in the cultivated Sahel -1 . Energy and water, J. Hydrol., 375, 204-216, 2009.
Reichstein, M., Falge, E., Baldocchi, D., Papale, D., Aubinet, M., Berbigier, P., Bernhofer, C., Buchmann, N., Gilmanov, T., Granier, A., Grünwald, T., Havránková, K., Ilvesniemi, H., Janous, D., Knohl, A., Laurila, T., Lohila, A., Loustau, D., Matteucci, G., Meyers, T., Miglietta, F., Ourcival, J.-M., Pumpanen, J., Rambal, S., Rotenberg, E., Sanz, M., Tenhunen, J., Seufert, G., Vaccari, F., Vesala, T., Yakir, D., and Valentini, R.: On the separation of net ecosystem exchange into assimilation and ecosystem respiration: review and improved algorithm, Glob. Change Biol., 11, 1424-1439, 2005.

Rodell, M., Houser, P. R., Jambor, U., Gottschalck, J., Mitchell, K., Meng, C.-J., Arsenault, K., Cosgrove, B., Radakovich, J., Bosilovich, M., Entin, J. K., Walker, J. P., Lohmann, D., and Toll, D.: The Global Land Data Assimilation System, B. Am. Meteorol. Soc., 85, 381-394, 2004.

Rosero, E., Yang, Z. L., Gulden, L. E., Niu, G. Y., and Gochis, D. J.: Evaluating Enhanced Hydrological Representations in Noah LSM over Transition Zones: Implications for Model Development, J. Hydrometeorol., 10, 600-622, 2009.

Ryu, Y., Kang, S., Moon, S.-K., and Kim, J.: Evaluation of land surface radiation balance derived from moderate resolution imaging spectroradiometer (MODIS) over complex terrain and heterogeneous landscape on clear sky days, Agr. Forest Meteorol., 148, 1538-1552, 2008.

Sellers, P. J.: Canopy reflectance, photosynthesis, and transpiration, II. The role of biophysics in the linearity of their interdependence, Remote Sens. Environ., 21, 143-183, 1987.

Swets, D. L., Reed, B. C., Rowland, J. D., and Marko, S. E.: A weighted least-squares approach to temporal smoothing of NDVI, in: ASPRS Annual Conference, From Image to Information, American Society for Photogrammetry and Remote Sensing, Portland, Oregon, 1999.

Wang, K., Wang, P., Li, Z., Cribb, M., and Sparrow, M.: A simple method to estimate actual evapotranspiration from a combination of net radiation, vegetation index, and temperature, J. Geophys. Res., 112, 15107-15114, 2007.

Williams, C., Hanan, N., Scholes, R. J., and Kutsch, W.: Complexity in water and carbon dioxide fluxes following rain pulses in an African savanna, Oecologia, 161, 469-480, 2009.

Wilson, K., Wilson, K., Goldstein, A., Falge, E., Aubinet, M., Baldocchi, D., Berbigier, P., Bernhofer, C., Ceulemans, R., Dolman, H., Field, C., Grelle, A., Ibrom, A., Law, B. E., Kowalski, A., Meyers, T., Moncrieff, J., Monson, R., Oechel, W., Tenhunen, J., Valentini, R., and Verma, S.: Energy balance closure at FLUXNET sites, Agr. Forest Meteorol., 113, 223-243, 2002.

World Bank: Spurring agricultural and rural development, in: Can Africa Claim the 21st Century?, World Bank, Washington, DC, 2000.

Zeng, N.: Drought in the Sahel, Science, 302, 999-1000, 2003.

Zeng, N. and Neelin, J. D.: The Role of Vegetation-Climate Interaction and Interannual Variability in Shaping the African Savanna, J. Climate, 13, 2665-2670, 2000. 